\title{
Service Provision and Product Differentiation: A Comment to "A Note on the Strategic Use of Service"
}

\author{
James Boswell \\ Auburn University Montgomery • Montgomery, AL \\ Evan Moore \\ Auburn University Montgomery • Montgomery, AL
}

\section{Abstract}

Hegji and Moore (2005, p. 140) state, "The bottom line for managers is that although the provision of service may at times seem attractive, in that increased services allow for higher prices, price competition should be considered the preferred long-run strategy." Contrary to their result we find that service provision is profitable in the long run and can be associated with lower prices. Additionally, we discuss the value of product differentiation. Our paper builds on their results in three ways: providing an additional setting of homogeneous goods duopoly, providing the profits under the three scenarios (Hegji and Moore's monopoly and differentiated price duopoly, and our homogeneous goods duopoly) with and without service provision, and a discussion of the managerial implications in terms of both service provision and product differentiation.

\section{Introduction}

Hegji and Moore (2005) present a model of service provision under two settings: a monopoly and a differentiated price duopoly. Their results indicate that prices are greater in the case of the duopoly, which is unexpected as monopoly pricing is typically greater than that of other market structures. They then discuss the implications of the model in terms of consumer surplus rather than profitability.

We build on their results in three ways: we provide an additional setting of homogeneous goods duopoly, we provide the profits under the three scenarios (Hegji and Moore's monopoly and differentiated price duopoly, and our homogeneous goods duopoly) with and without service provision, and we discuss the managerial implications in terms of both service provision and product differentiation. Contrary to Hegji and Moore's conclusion that ". . . the provision of service may at times seem attractive, in that increased services allow for higher prices, price competition should be considered the preferred long-run strategy," we find that service provision is profitable in the long run and discuss the value of product differentiation. 
Additionally, our results reveal necessary restrictions on the differentiated price duopoly model presented by Hegji and Moore. These findings provide insight as to whether product differentiation is worthwhile.

Much of the remainder of the paper is of a technical, or mathematical, nature. We would like to briefly mention some of the managerial implications at this point for those readers who are not interested in the technical details. Contrary to the findings of Hegji and Moore, our results indicate that managers should consider product differentiation as a means for increasing profitability if they are competing in markets where the product has accompanying service provision that is of value to consumers. However, if product differentiation is not possible, then managers should determine if demand for their product is affected by the level of service associated with the product being sold. Our results indicate that if demand is indeed affected by the level of service, then service provision can lead to greater profitability with lower prices for non-differentiated goods. This result provides a counterpoint to Hegji and Moore's claim that increased services results in higher prices. According to the framework used in this paper, and those of Hegji and Moore (2005) and Pepall, Richards, and Norman (2002), the increased profitability occurs as increasing service leads to increases in consumer willingness to pay. This increase can induce a consumer who was not previously buying the product, but seriously considering purchasing, to now buy the product; this potential buyer is known in the economics literature as a marginal consumer. As the number of marginal consumers increases, there is generally a greater return to service provision.

The remainder of the paper is organized as follows. Section II presents the results of duopolists providing services in a strategic setting involving homogeneous, i.e. identical, goods. Section III presents the profits under the three scenarios with service provision and discusses the limits of differentiation. Section IV presents the profits under the three scenarios without service provision, allowing for a comparison with the results in Section III revealing that profitability likely increases with service provision. Finally, we conclude with a summary and implications for managers.

\section{The Provision of Services under a Homogeneous Goods Cournot Duopoly}

A critical assumption in Hegji and Moore's work involves the derivation of the demand specification for the Bertrand price setting. These authors assume that if the firms are producing non-differentiated or homogeneous goods, then each of the duopolists begins with half of the monopoly's share of the market. Their differen- 
tiation parameter, $\beta$, indicates that differentiation occurs if $\beta>0$ and homogeneous goods occur if $\beta=0$. As such it is then no surprise that the results of their duopoly model simplify to that of the monopoly outcome when $\beta=0$. However, in a competitive environment with firms producing homogeneous goods, it would be unusual to find a duopoly behaving collectively as a monopolist in a static setting, and this is even more unusual given the firms' cost structures in their model. In many instances this could easily be viewed as a collusive arrangement. ${ }^{1}$ As such, Hegji and Moore's framework is reasonable for differentiated goods but does not accurately capture the nature of competition with homogeneous goods. A Cournot type of modeling approach is more appropriate in this setting.

Let us now consider such a Cournot duopoly, with each firm having costs of $T C_{i}=q_{i}(C+\varphi S)$ as in Hegji and Moore. Begin by expressing quantity demanded for firm $i$ 's product as $q_{\mathrm{i}}=S_{\mathrm{i}}(A-P)$, and aggregating across both firms. Since firms compete over output or quantity, in a Cournot framework this equation is expressed in its inverse demand form

$$
P=A-\frac{\left(q_{1}+q_{2}\right)}{S_{1}+S_{2}}
$$

Using (1) results in the profit function for firm $i$

$$
\Pi_{i}\left(q_{i}, S_{i}\right)=\left(A-\frac{\left(q_{1}+q_{2}\right)}{S_{1}+S_{2}}\right) q_{i}-\left(C+\varphi S_{i}\right) q_{i} .
$$

Differentiating (2) with respect to $\mathrm{q}_{\mathrm{j}}$ yields the reaction function

$$
q_{i}=\frac{\left(A-\varphi S_{i}-C\right)\left(S_{1}+S_{2}\right)}{2}-\frac{q_{j}}{2} .
$$

Solving (3) results in firm and market outputs of

$$
\begin{aligned}
& q_{i}=\frac{\left(A-2 \varphi S_{i}+\varphi S_{j}-C\right)\left(S_{1}+S_{2}\right)}{3}, \\
& q_{1}+q_{2}=\frac{2\left(A-\varphi\left(S_{i}\right)-C\right)\left(S_{1}+S_{2}\right)}{3} .
\end{aligned}
$$

The optimal level of customer service is obtained by differentiating (2) with respect to $S_{i}$, which yields the condition

$$
\frac{\delta \Pi_{i}}{\delta S_{i}}=q_{i}\left[\frac{q_{1}+q_{2}}{\left(S_{1}+S_{2}\right)^{2}}\right]-\varphi q_{i}=0 .
$$


Solving (6) and use of (5) yields the optimal level of total service for the Cournot duopoly

$$
S^{*}=S_{1}+S_{2}=\frac{(A-C)}{2 \varphi}
$$

And, use of (5) in (7) results in the market price

$$
P=\frac{A+C}{2} \text {. }
$$

As with the monopoly and Bertrand models discussed in Hegji and Moore, price in the Cournot duopoly is a markup above production and service costs. As expected, the Cournot price is less than the monopoly price and, therefore, lower than prices in the Bertrand market.

The level of service in the Cournot duopoly has some interesting features. Note that total level of service provided by the two firms is determined in equilibrium, but the distribution of service between the duopolists, at first glance, is indeterminate. A natural assumption to make is that each duopolist provides one half of the total market level of service. Given that the Cournot duopolists charge the same price, if either firm offers a lower level of service than its competitor, then customers will purchase the product from the firm offering higher services. Therefore, in an efficient equilibrium the firms will offer identical levels of service as customers will not be searching for a firm offering a higher level of service.

Under the assumption of equal service provision, each duopolist provides less service than the monopoly provider of service. Compare one half of equation (7) with Hegii and Moore's equation (4HM), $S^{*}=\frac{(A-C)}{3 \varphi}$. This is expected in a market with two firms producing a homogeneous good. The tendency is for each firm to provide less service than if it were the only producer since the market price is lower for each firm in the duopoly.

Given the findings of Hegji and Moore, it is no surprise that the price and level of service in the Cournot model are lower than those in the Bertrand case. However, while service provision is lower in the Cournot duopoly than that of the Bertrand case, consumer surplus is greater in the Cournot case. The loss in consumer welfare due to lower service provision is more than offset by the gain due to the accompanying lower prices. In their model of service provision as service hours, Shy and Stenbacka (2006, p.763) find that service is ". . inefficiently low from a social point of view." Our results suggest that lower levels of service can be welfare enhancing if prices are suitably lower. This could alternatively be interpreted as the 
Bertrand model of Hegji and Moore resulting in service levels, and ultimately prices, that are inefficiently high from a social point of view.

\section{Profits of Service Provision under Three Settings}

It is a straightforward exercise to calculate the profits of the monopolist $\left(\Pi_{M}\right)$ and each Bertrand duopolist $\left(\Pi_{B}\right)$ using the results of Hegji and Moore. The profit for a Cournot duopolist $\left(\Pi_{C}\right)$ is calculated using the findings above. The per firm profits are

$$
\Pi_{M}=\frac{(A-C)^{3}}{27 \varphi}, \Pi_{B}=\frac{(A-C+\beta C)^{3}}{2 \varphi(2+2 \beta)^{3}}, \Pi_{C}=\frac{(A-C)^{3}}{32 \varphi} .
$$

A comparison of the profits under each scenario reveals some insights. Note that the profitability of a Bertrand competitor $\left(\Pi_{B}\right)$ is equal to $1 / 2$ of that of the monopolist $\left(\Pi_{M}\right)$ when $\beta=0$. However, without any differentiation between products, the profits are more accurately presented by those of a Cournot competitor $\left(\Pi_{C}\right)$, which are considerably greater than those of the Bertrand case with no differentiation. A comparison of the profits of the Bertrand and Cournot competitors reveals that

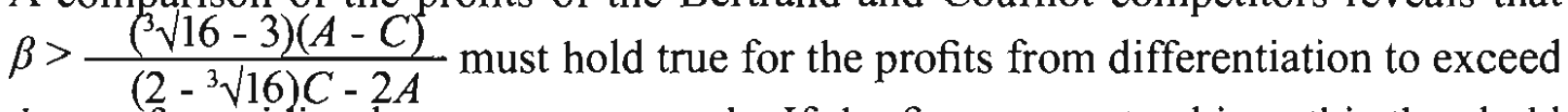
those of providing homogeneous goods. If the firms cannot achieve this threshold level of differentiation then our result is similar to that of Egli (2007) in that profit maximizing firms would prefer zero product differentiation. This result also supports the findings of Zanchettin (2006, p.999) that product differentiation can reduce profits, “. . implying that a local incentive towards less differentiation may arise."

Nevertheless, it is evident that for a firm engaged in any degree of product differentiation, increasing differentiation is profitable as the derivative of $\Pi_{B}$ with respect to $\beta$ is $\frac{d \Pi_{B}}{d \beta}=\frac{3(2 A+C)(A+(\beta-1) C)^{2}}{2 \varphi(3-2 \beta)^{4}}$, which is positive. This is a standard result for symmetric firms (Zanchettin, 2006, p. 999).

Hegji and Moore note that consumer surplus in the Bertrand market decreases ". . . as $\beta$ increases from 0 to 1 ." However, a closer inspection of their equation $(10 \mathrm{HM}), C S_{B}=\frac{(A-C+\beta C)^{2}(A(1-2 \beta)-C)}{2 \varphi\left(3-2 \beta^{3}\right.}$, reveals that the maximum possible value for $\beta$ is $1 / 2$. To be more specific,

$$
\beta \leq=\frac{(A-C)}{2 A} \text {. }
$$

When the equality in (10) holds, consumer surplus in the Bertrand market $\left(\mathrm{CS}_{B}\right)$ is zero. For any value of $\beta$ that exceeds $(A-C) / 2 A$, the consumer surplus would be 
negative indicating that consumers would not purchase the good. These findings restrict the plausible values of $\beta$ to $\frac{\beta \sqrt{16}-3)(A-C)}{(2-\sqrt[3]{16}) C-2 A}<\beta \leq \frac{A-C}{2 A}$, such that consumer surplus in the Bertrand market decreases and profits increase as $\beta$ increases in the range.

Suppose the Bertrand competitors achieve the highest possible level of differentiation such that equation (10) results in equality. In this case the profits for a Bertrand competitor are $\Pi_{B}=\frac{(A-C)^{3}}{16 \varphi}$. This is the highest possible profit, assuming no cost of differentiating, which is realized by maximizing differentiation. This finding supports the principle of maximum differentiation presented by D'Aspremont, Gabszewicz, and Thisse (1979). These profits are markedly higher than those of a single monopoly firm or for the Cournot competitors for homogeneous goods. In fact, the Bertrand competitors' profits are double those of the Cournot competitors.

\section{Profits without Service Provision under Three Settings}

To provide a basis for comparison, consider the scenarios presented above in the standard context without firms providing services. This results in demand functions of $Q=A-P$ in the monopoly case and $q_{i}=\left(100-P_{i}+P_{j}\right) / 2$ in the Bertrand market, and an inverse demand function of $P=100-q_{1}-q_{2}$ in the Cournot market. The cost function for any firm is $T C_{i}=C q_{i}$. The resulting equilibrium profits are

$$
\pi_{M}=\frac{(A-C)^{2}}{4}, \pi_{B}=\frac{(A+2 C(\beta-1)(A+\beta C)}{2(\beta-2)^{2}}, \pi_{C}=\frac{(A-C)^{2}}{9}
$$

Comparing these profits with those under service provision indicates that service provision is profitable for likely values of $\varphi^{3}$. And in an interesting twist, note that in the case of homogeneous goods provision the profits for each of the Cournot competitors more closely approximate the profits of the monopolist. Without service provision a Cournot firm earns 4/9 of the monopolist's profits, yet with service provision his profit increases to $27 / 32$ of that of the monopolist. Service provision may indeed be profitable.

An underlying feature of the scenarios presented in Hegji and Moore is that the markets discussed involve barriers to entry; i.e. monopoly and two versions of duopoly. Hence, their discussion of entry by possible competitors is not relevant; if entry is possible, it would occur as the firms in both of their settings are earning positive economic profits. 


\section{Summary and Managerial Implications}

Hegji and Moore (2005, p. 140) conclude with, "The bottom line for managers is that although competition in the provision of service may at times seem attractive, in that increased services allow for higher prices, price competition should be considered the preferred long-run strategy." The findings presented here suggest something different in that managers should consider product differentiation as a means for increasing profitability assuming the necessary threshold level can be obtained. We have also shown that increasing the level of differentiation can increase profits. ${ }^{4}$ Additionally, allowing for the necessary barriers to entry that give rise to the two firm Bertrand market, the provision of services can indeed be a profitable endeavor in the long run.

However, suppose product differentiation is not an option for managers. Our results indicate that managers of firms selling homogeneous goods should closely consider the nature of demand for their products. If demand for the product is indeed a function of service provision then, contrary to the quote above from Hegji and Moore, competition in the provision of services is both profitable for the firms and coincides with lower prices for the consumers. This is due to the nature of demand as in equations (1HM), $Q(P, S)=S(A-P)$ and $(5 \mathrm{HM}), q_{i}=S_{i}\left(A-P_{i}+\beta P_{j}\right) / 2$ of Hegji and Moore, and equation (1) above where "... an increase in the service level...increases consumer willingness to pay for the good, and the increase is proportionately greater for the marginal consumer" (Pepall et al., 2002, p. 487). In both the differentiated and homogeneous goods cases, service competition can indeed be a viable and profitable long run strategy.

\section{Appendix}

\section{Conditions regarding $\varphi$ and profits:}

In the monopoly case, profits under service provision will exceed those without service if $\varphi<\frac{4(A-C)}{27}$

In the Bertrand case, profits under service provision will exceed those without service if $\varphi<\frac{(\beta-2)^{2}(A+(\beta-1) C)^{3}}{(3+2 \beta)^{3}\left(A^{2}+A(3 \beta-2) C+2(\beta-1) \beta C^{2}\right)}$.

In the Cournot case, profits under service provision will exceed those without service if $\varphi<\frac{9(A-C)}{32}$. 


\section{References}

D'Aspremont, C., Gabszewicz, J., \& Thisse, J. (1979). On hotelling's "stability in competition." Econometrica, 47, 1145-1150.

Egli, A. (2007). On stability in competition: Tying and horizontal product differentiation. Review of Industrial Organization, 30, 29-38.

Hegji, C. \& Moore, E. (2005). A note on the strategic use of service. Journal of Business Strategies, 22, 135-141.

Mankiw, N. (2009). Principles of economics (5th ed.). Florence, KY: South-Western Cengage Learning.

Pepall, L., Richards, D., \& Norman, G. (2002). Industrial organization: Contemporary theory and practice (2nd ed.). Mason, $\mathrm{OH}$ : Mason South-Western.

Shy, O., \& Stenbacka, R. (2006). Service hours with asymmetric distributions of ideal service time. International Journal of Industrial Organization, 24, 763-771.

Zanchettin, P. (2006). Differentiated duopoly with asymmetric costs. Journal of Economics \& Management Strategy, 15, 999-1015.

\section{Endnotes}

1. Particulary if the firms have constant marginal costs of production. Mankiw's (2009, p. 367) textbook, among many textbooks and articles, uses an example where a collusive outcome leads to a market that is, ". . . in effect served by a monopoly." However, in the Cournot model presented in this paper the collusive agreement would not be to split the monopolist's output and service; this is due to the quadratic nature of production costs. While not the focus of this paper, a glance at the profits in equation (9) reveals that a Cournot competitor would rather engage in competition, earning $\Pi_{C}$, than a collusive agreement earning half of the monopolist's profits, $1 / 2 \Pi_{\mathrm{M}}$. Note that the Cournot competitors would each produce more than half of the monopolist's output in a collusive agreement in our model.

2. To aid the reader, equations from Hegji and Moore (2005) that are referred to in the current paper are denoted as (\#HM), where \# is the equation number.

3. It is possible for service provision not to be more profitable, but unlikely. The necessary values of $\varphi$ for this not to be the case are provided in the appendix.

4. This is contingent on the marginal revenue being greater than or equal to the marginal cost of increased differentiation. 


\section{Biographical Sketches of Authors}

James Boswell obtained a B.S. in mathematics with a concentration in economics in December of 2008. He will begin graduate study in economics in the fall of 2009. His research interests include industrial organization, game theory, and mathematical economics.

Dr. Moore joined the Department of Economics at Auburn University Montgomery in 2002 . He is currently an associate professor and Head of the department. His primary teaching interests are industrial organization, game theory, and microeconomic theory. His primary areas of research include industrial organization and experimental economics. He has published in a variety of journals including the American Economic Review. 